\title{
Preparation, Characterization, and Mechanistic Understanding of Pd-Decorated ZnO Nanowires for Ethanol Sensing
}

\author{
Xiao Deng, ${ }^{1,2,3}$ Shengbo Sang, ${ }^{1,2}$ Pengwei Li, ${ }^{1,2}$ Gang Li, ${ }^{1,2}$ Fanqin Gao, ${ }^{1,2}$ Yongjiao Sun, \\ Wendong Zhang, ${ }^{1,2}$ and Jie $\mathrm{Hu}^{1,2}$ \\ ${ }^{1}$ MicroNano System Research Center, College of Information Engineering, Taiyuan University of Technology, \\ Taiyuan, Shanxi 030024, China \\ ${ }^{2}$ Key Lab of Advanced Transducers and Intelligent Control System of the Ministry of Education, \\ Taiyuan University of Technology, Taiyuan, Shanxi 030024, China \\ ${ }^{3}$ College of Physics and Optoelectronics, Taiyuan University of Technology, Taiyuan, Shanxi 030024, China
}

Correspondence should be addressed to Wendong Zhang; wdzhang@tyut.edu.cn and Jie Hu; hujie@tyut.edu.cn

Received 5 October 2013; Accepted 2 December 2013

Academic Editor: Sheng-Rui Jian

Copyright () 2013 Xiao Deng et al. This is an open access article distributed under the Creative Commons Attribution License, which permits unrestricted use, distribution, and reproduction in any medium, provided the original work is properly cited.

$\mathrm{ZnO}$ nanowires ( $\mathrm{ZnO}-\mathrm{NWs}$ ) and Pd-decorated $\mathrm{ZnO}$ nanowires (Pd-ZnO-NWs) were prepared by hydrothermal growth and characterized by scanning electron microscopy (SEM) and X-ray diffraction (XRD). When used for gas sensing, both types of nanowires showed a good selectivity to ethanol but a higher sensitivity and lower operating temperature were found with Pd-ZnO-NWs sensors comparing to those of $\mathrm{ZnO}-\mathrm{NWs}$ sensor. When exposed to $200 \mathrm{ppm}$ ethanol, our $\mathrm{ZnO}-\mathrm{NWs}$ sensor showed a sensitivity of about 2.69 at $425^{\circ} \mathrm{C}$ whereas 1.3 at. \% Pd-ZnO-NWs sensor provided a $57 \%$ more detection sensibility at $325^{\circ} \mathrm{C}$. In addition, both response and recovery times of $\mathrm{Pd}-\mathrm{ZnO}-\mathrm{NWs}$ sensors were significantly reduced ( $9 \mathrm{~s}$ ) comparing to the $\mathrm{ZnO}-\mathrm{NWs}$. Finally, $\mathrm{Pd}-\mathrm{ZnO}$-NWs sensor also showed a much lower detection limit of about $1 \mathrm{ppm}$. The sensing mechanism of Pd-ZnO-NWs sensors has also been clarified, thereby providing a new perspective for further improvement of the sensing performance of ethanol sensors.

\section{Introduction}

Semiconducting metal oxides are widely used in environmental monitoring, industrial safety monitoring and medical diagnosis [1-3]. Among different types of metal oxides, zinc oxide $(\mathrm{ZnO})$ is of great interest because of its versatile suitability for a large variety of applications. For example, it can be used in gas sensors [4], solar cells [5], field-effect transistors [6], photodetectors [7], and photocatalysts [8]. In particular, $\mathrm{ZnO}$ can be used in toxic [2] and combustible [9] gas sensors.

Comparing to the bulk material, micro- and nanostructured $\mathrm{ZnO}$ can provide a much improved performance for device applications [10]. Recently, efforts have been devoted to the realization of gas sensor using $\mathrm{ZnO}$ thin films [11], nanoparticles [12], and nanowires [13]. Among them, $\mathrm{ZnO}$ NWs are regarded as the most promising candidate for high sensitivity gas sensors for their higher specific surface area and larger length-to-diameter ratio [14]. It has also been shown that surface decoration of $\mathrm{ZnO}$ with noble metal elements such as $\mathrm{Pd}, \mathrm{Ag}, \mathrm{Pt}$, and $\mathrm{Au}$ can largely improve the sensitivity of the device because of the modification of the energy band gap and the increase of the carrier concentration [15-19]. Pd, for example, is one of the most versatile catalytic materials for its excellent oxidation capability of converting hydrocarbons at lower temperature [20]. Hsueh et al. reported that the response of Pd-ZnO-NWs can be increased from 1.56 to 2.60 when exposed to $500 \mathrm{ppm}$ ethanol at $230^{\circ} \mathrm{C}$, with a response of a few seconds and a recovery time of more than 100 seconds, respectively [21]. Roy et al. also investigated the Pd-sensitized $\mathrm{ZnO}$ nanorods for ethanol sensing, the results show that the response magnitude, response and recovery time are $94 \%, 14 \mathrm{~s}$ and $70 \mathrm{~s}$, respectively, when exposed to $1530 \mathrm{ppm}$ ethanol (in air) at an optimum operating temperature of $200^{\circ} \mathrm{C}$ [22]. Note that despite the significant 
improvement in sensitivity, there are still large challenge for improvement of the recovery time and the detection limit of these $\mathrm{ZnO}$ ethanol sensors.

In this work, we studied the sensing performance of $\mathrm{ZnO}-\mathrm{NWs}$ with or without Pd decoration. Vertical $\mathrm{ZnO}$ NWs with an average diameter of $80 \mathrm{~nm}$ and a length of $5 \mu \mathrm{m}$ were prepared by hydrothermal growth. To investigate the detection sensitivities of $\mathrm{ZnO}-\mathrm{NW}$ s and $\mathrm{Pd}-\mathrm{ZnO}-\mathrm{NWs}$, $\mathrm{Pd}$ nanoparticles with various concentrations were deposited on the surface of $\mathrm{ZnO}-\mathrm{NW}$. The results show that $\mathrm{ZnO}$ NWs and Pd-ZnO-NWs can have the highest responses and gas selectivity to ethanol at different operating temperatures. Comparing to the $\mathrm{ZnO}-\mathrm{NW}$ s sensor, $\mathrm{Pd}-\mathrm{ZnO}-\mathrm{NWs}$ (1.3 at. $\%)$ sensor showed a much improved sensitivity and responserecovery time to ethanol.

\section{Experiment}

2.1. Preparation of $\mathrm{ZnO}-\mathrm{NWs}$. Vertically aligned $\mathrm{ZnO}-\mathrm{NWs}$ arrays were grown on glass substrate by two-step hydrothermal method as previously reported [25]. Firstly, $0.2 \mathrm{mM}$ $\mathrm{ZnAc}\left(\mathrm{Zn}\left(\mathrm{CH}_{3} \mathrm{CO}_{2}\right)_{2}, 99.99 \%\right.$, Sigma-Aldrich) was dissolved in $40 \mathrm{~mL}$ of ethanol $\left(\mathrm{C}_{2} \mathrm{H}_{5} \mathrm{OH}, 99.8 \%\right.$, Guangfu) solution to form a seed solution, which was uniformly dropped on the substrate. Afterwards, the glass sheet was put into an ethanol solution for rinsing for 10 seconds, and the sample was placed on a hot plate for 30 minutes at $300^{\circ} \mathrm{C}$. The above process was repeated several times to form a seed layer. Secondly, a growth solution was prepared by dissolving $10 \mathrm{mM}$ zinc nitrate $\left(\mathrm{Zn}\left(\mathrm{NO}_{3}\right)_{2} \cdot 6 \mathrm{H}_{2} \mathrm{O}, 99.0 \%\right.$, Sigma-Aldrich) and $5 \mathrm{mM}$ HMTA $\left(\mathrm{C}_{6} \mathrm{H}_{12} \mathrm{~N}_{4}, 99.5 \%\right.$, Sigma-Aldrich) in $400 \mathrm{~mL}$ deionized water with magnetical stirring for 30 minutes and then gradually adding $18.8 \mathrm{~mL}$ of ammonia $\left(\mathrm{NH}_{4} \mathrm{OH}, 28.0 \%\right.$, Sigma-Aldrich) until the end of preparation. Next, the glass sheet with the pretreated $\mathrm{ZnO}$ seed layer facing downward was immersed in the growth solution for 8 hours at $90^{\circ} \mathrm{C}$. Finally, the glass sheet was washed with deionized water and dried in nitrogen.

To obtain Pd-ZnO-NWs, the ZnO-NWs were dipped in an ethanol solution of $9.6 \mathrm{mM}$ palladium chloride $\left(\mathrm{PdCl}_{2}\right.$, $99.9 \%$, Sigma-Aldrich) for $8 \mathrm{~s}$ and then dried using an air gun. The cycle was repeated several times. The Pd-ZnO-NWs were annealed at $500^{\circ} \mathrm{C}$ for 1 hour and then cooled down to room temperature. To improve the stability and the repeatability of the gas sensors, samples of $\mathrm{ZnO}-\mathrm{NW}$ s and $\mathrm{Pd}-\mathrm{ZnO}-\mathrm{NW}$ were aged at $200^{\circ} \mathrm{C}$ for 10 days. Finally, a conductive silver paste was uniformly coated on the sample to form electrodes to ensure the electrical contact between the nanowires and probes.

2.2. Characterization Methods. The morphology of $\mathrm{ZnO}-$ NWs and Pd-ZnO-NWs was observed using scanning electron microscope (SEM, Hitachi S-3400N), equipped with Xray energy dispersive spectroscope (EDS, Bruker). The crystal structure and components of samples were characterized by $\mathrm{X}$-ray diffraction technique (XRD, DRIGC-Y 2000A) with $\mathrm{Cu}$ $\mathrm{K} \alpha$ radiation $(\lambda=0.15406 \mathrm{~nm})$ at $30 \mathrm{kV}$.

The gas sensing properties of the fabricated sensors were tested using the intelligent analysis system (CGS-1TP, Beijing

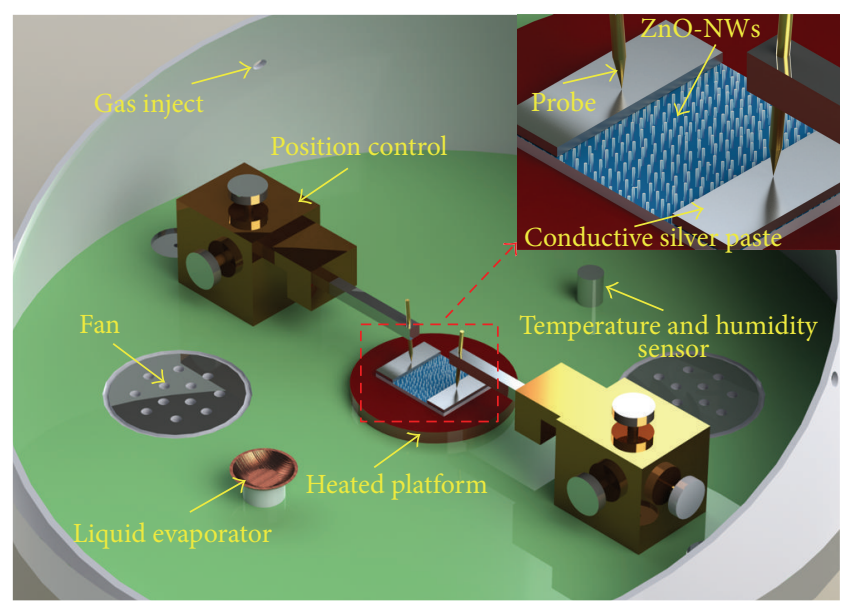

FIGURE 1: Schematic illustration of a set-up for gas sensitivity analyses. The insert shows a typical device configuration of $\mathrm{ZnO}$ NWs sensor.

Elite Tech Co., Ltd, China). Figure 1 shows the schematic of the gas sensitivity analysis system. The gas sensor is fixed on the heated platform until the resistance of the sensor is stable. Then the target gas is injected into the testing chamber (with a testing volume of $18 \mathrm{~L}$ ) by a microinjector, and two rotating fans in the testing chamber make the gas mixed homogeneously. After the resistance of the sensor reaches a new stable value, the testing chamber is opened to refill air. The response and recovery times are defined as the time needed for $90 \%$ of total resistance change after the sensor exposed to the testing gas and to the air, respectively.

The target gas at different concentrations was prepared by a static state method. The whole process of gas dilution could be approximately considered as an isobaric process, resulting in the following relationship between the volume of injected liquid, and the concentration of target gas [26]:

$$
V_{\text {liquid }}=\frac{V_{s} C_{\text {gas }} M}{22.4 \rho d} \times 10^{-9} \text {, }
$$

where $V_{\text {liquid }}$ is the volume of injected liquid, $V_{s}$ is the volume of testing chamber, $C_{\text {gas }}$ is the concentration of target gas, $M$ is the molecular weight of liquid, $\rho$ is the density of liquid, and $d$ is the purity of liquid.

Considering the n-type semiconductor characteristic of $\mathrm{ZnO}$, the response value of gas sensor to reductive gas can be defined as $S=R_{a} / R_{g}$, where $R_{a}$ and $R_{g}$ are the resistance of sensor in air and in target gas, respectively.

\section{Results and Discussion}

3.1. Structural Characterization. Figures 2(a) and 2(b) show the top-view and side-view SEM images of $\mathrm{ZnO}-\mathrm{NW}$. It can be observed that the $\mathrm{ZnO}-\mathrm{NW}$ s vertically grown on the substrate are well aligned. The diameter and length of the nanowires are, respectively, about $70-100 \mathrm{~nm}$ and $5 \mu \mathrm{m}$. Comparing the SEM pictures of $\mathrm{ZnO}-\mathrm{NW}$ and $\mathrm{Pd}-\mathrm{ZnO}-$ NWs shown in Figures 2(c) and 2(d), it is clear that the 

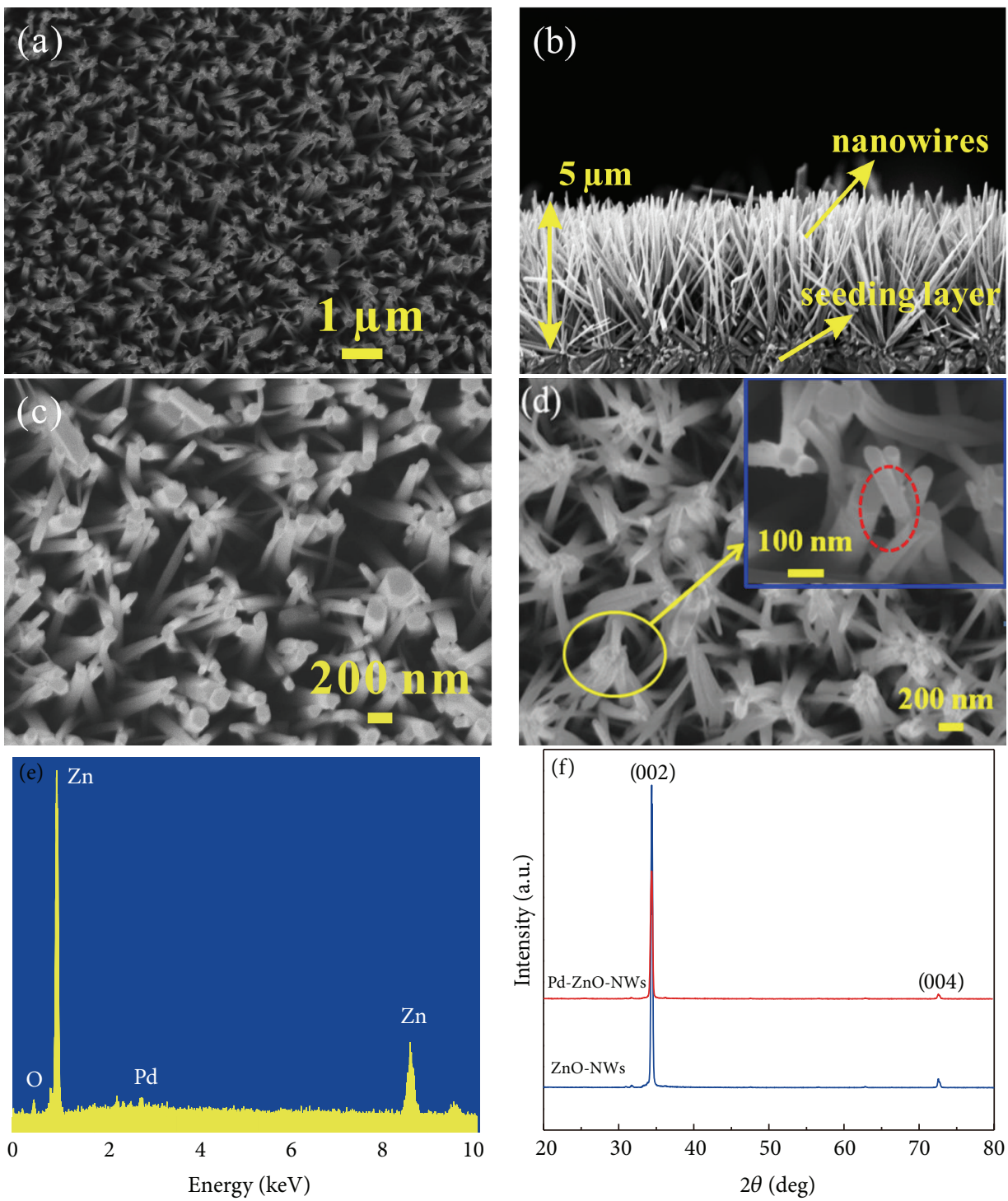

Figure 2: (a) Top-view and (b) side-view SEM images of ZnO-NWs grown on the substrate, (c) magnified top-view SEM images of ZnONWs and (d) Pd-ZnO-NWs (the inserted image shows the nanoparticles of Pd on ZnO-NWs), (e) EDS spectrum of Pd-ZnO-NWs, and (f) the XRD spectra of $\mathrm{ZnO}-\mathrm{NWs}$ and Pd-ZnO-NWs.

morphology of ZnO-NWs remains unchanged after Pd decoration. However, the small particles on $\mathrm{ZnO}-\mathrm{NWs}$ surface can be seen in the inserted image of Figure 2(d). The results of EDS analyses are shown in Figure 2(e), indicating that the sample of Pd-ZnO-NWs is indeed composed of $\mathrm{Zn}, \mathrm{O}$, and $\mathrm{Pd}$. This demonstrates that Pd has been successfully decorated on the surface of $\mathrm{ZnO}$-NWs.

To investigate the crystalline structures of $\mathrm{ZnO}-\mathrm{NWs}$ and Pd-ZnO-NWs, XRD spectra of the samples are obtained as shown in Figure 2(f). The diffraction peaks in the XRD patterns are the same as the standard card (JCPDS 36-1451) with a wurtzite structure of $\mathrm{ZnO}$ by indexing. A strong and sharp peak located at (002) crystal plane of the prepared $\mathrm{ZnO}-\mathrm{NWs}$ reveals their high quality crystallinity and $c$ axis orientation [27]. No diffraction peaks of Pd could be observed, however, in the XRD pattern of Pd-ZnO-NWs, due probably to the fact that the Pd content is much lower than that of $\mathrm{Zn}$ or O in Pd-ZnO-NWs $[28,29]$.

3.2. Gas Sensing Properties. In order to confirm a good gas selectivity of the sensors, we have performed sensing studies of $\mathrm{ZnO}-\mathrm{NWs}$ and $\mathrm{Pd}-\mathrm{ZnO}-\mathrm{NWs}$ for various gases such as $\mathrm{CH}_{4}, \mathrm{CO}, \mathrm{CH}_{3} \mathrm{OH}, \mathrm{CH}_{3} \mathrm{COCH}_{3}$, and $\mathrm{C}_{2} \mathrm{H}_{5} \mathrm{OH}$ (Figure 3). The concentration of all the analytes is $200 \mathrm{ppm}$. Figure 3(a) shows that the $\mathrm{ZnO}-\mathrm{NWs}$ sensor does not respond to $\mathrm{CH}_{4}$ and $\mathrm{CO}$ gases in the whole range of testing temperatures. On the other hand, the same sensor shows the detectable signal with $\mathrm{CH}_{3} \mathrm{OH}, \mathrm{CH}_{3} \mathrm{COCH}_{3}$, and $\mathrm{C}_{2} \mathrm{H}_{5} \mathrm{OH}$ gases, indicating also a maximum response at a temperature of $425^{\circ} \mathrm{C}$. The maximum sensitivities to $\mathrm{CH}_{3} \mathrm{COCH}_{3}$ and $\mathrm{CH}_{3} \mathrm{OH}$ are found to be 1.68 and 1.30, respectively, which are much lower compared to that of $\mathrm{C}_{2} \mathrm{H}_{5} \mathrm{OH}(\sim 2.69)$. The gas selectivity 


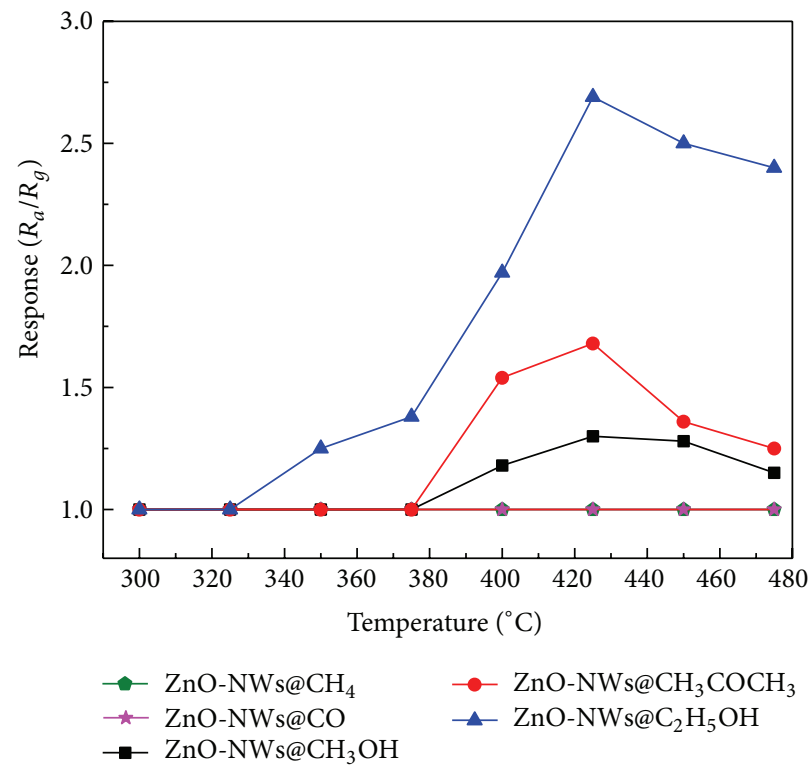

(a)

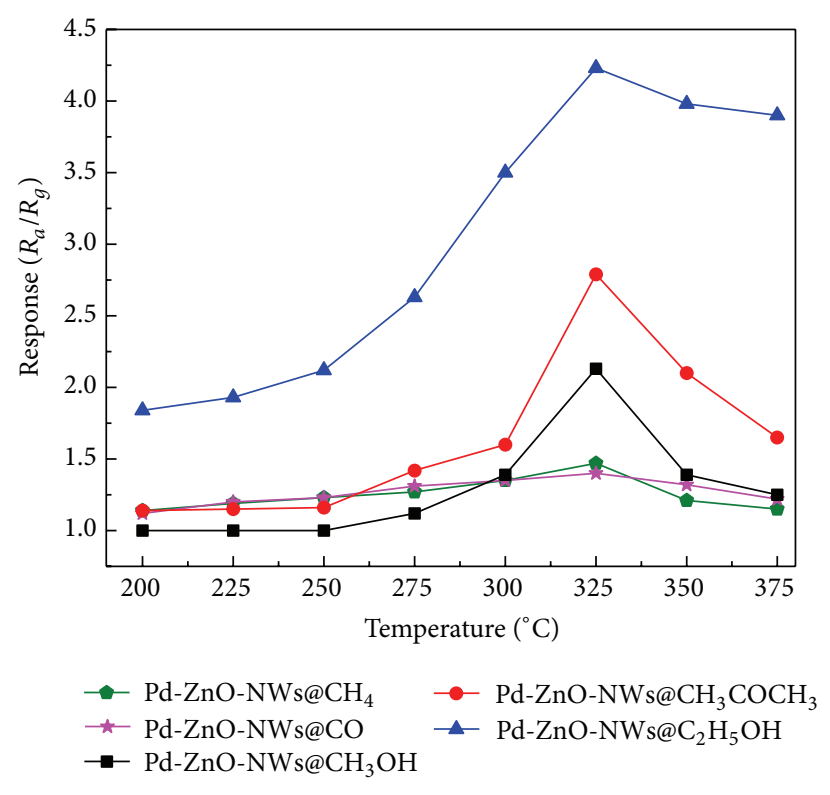

(b)

Figure 3: Response of (a) ZnO-NWs and (b) Pd-ZnO-NWs to different gases of $200 \mathrm{ppm}$ concentration at various operating temperatures.

TABLE 1: Selectivity factor $(Q)$ of the sensors fabricated by ZnO-NWs and Pd-ZnO-NWs. $\left(Q=S_{\text {ethanol }} / S_{\text {other }}\right.$, where $S_{\text {ethanol }}$ and $S_{\text {other }}$ are the responses of the sensors to $200 \mathrm{ppm}$ ethanol and other gases, resp.).

\begin{tabular}{lccccc}
\hline & \multicolumn{5}{c}{ Target gases } \\
& $\mathrm{C}_{2} \mathrm{H}_{5} \mathrm{OH}$ & $\mathrm{CH}_{4}$ & $\mathrm{CO}$ & $\mathrm{CH}_{3} \mathrm{OH}$ & $\mathrm{CH}_{3} \mathrm{COCH}_{3}$ \\
\hline $\begin{array}{l}\text { Q factor of } \\
\text { ZnO-NWs }\end{array}$ & 1 & 2.69 & 2.69 & 2.07 & 1.60 \\
$\begin{array}{l}Q \text { factor of } \\
\text { Pd-ZnO-NWs }\end{array}$ & 1 & 2.88 & 3.02 & 1.99 & 1.52 \\
\hline
\end{tabular}

experiments were also carried out with $\mathrm{Pd}-\mathrm{ZnO}-\mathrm{NW}$ s sensor (Figure 3(b)). The results show that the sensor is sensitive to all testing gases after Pd was decorated, and the maximum responses to different gases appear at the same temperature of $325^{\circ} \mathrm{C}$, which is lower than that of $\mathrm{ZnO}-\mathrm{NWs}$. Now, the maximum sensitivities to $\mathrm{C}_{2} \mathrm{H}_{5} \mathrm{OH}, \mathrm{CH}_{3} \mathrm{COCH}_{3}, \mathrm{CH}_{3} \mathrm{OH}$, $\mathrm{CH}_{4}$, and $\mathrm{CO}$ are $4.23,2.79,2.13,1.47$, and 1.4 , respectively.

To evaluate the gas selectivity of sensors, we define a selectivity factor (Q) as $Q=S_{e} / S_{o}$ [28], where $S_{e}$ and $S_{o}$ are the responses of the sensors to $200 \mathrm{ppm}$ ethanol and $200 \mathrm{ppm}$ of other gases in this work, respectively. The bigger the value of $Q$ of a sensor, the higher the selectivity to the ethanol gas. From the results listed in Table 1, we can find that the two types of sensors have a better selectivity to ethanol at the ambient of $\mathrm{CO}$ or $\mathrm{CH}_{4}$. Clearly, the sensing selectivity has been increased after $\mathrm{Pd}$ decoration.

To investigate the sensing properties of $\mathrm{ZnO}-\mathrm{NWs}$ and $\mathrm{Pd}-\mathrm{ZnO}-\mathrm{NW}$ for ethanol gas, the $\mathrm{ZnO}-\mathrm{NW}$ grown on the substrate were dipped in an ethanol solution of $9.6 \mathrm{mM}$ palladium chloride and this process was repeated 3,5 , and 7 times, respectively. We refer to these samples as $\mathrm{Pd}-\mathrm{ZnO}-$ NWs-3, Pd-ZnO-NWs-5, and Pd-ZnO-NWs-7, representing

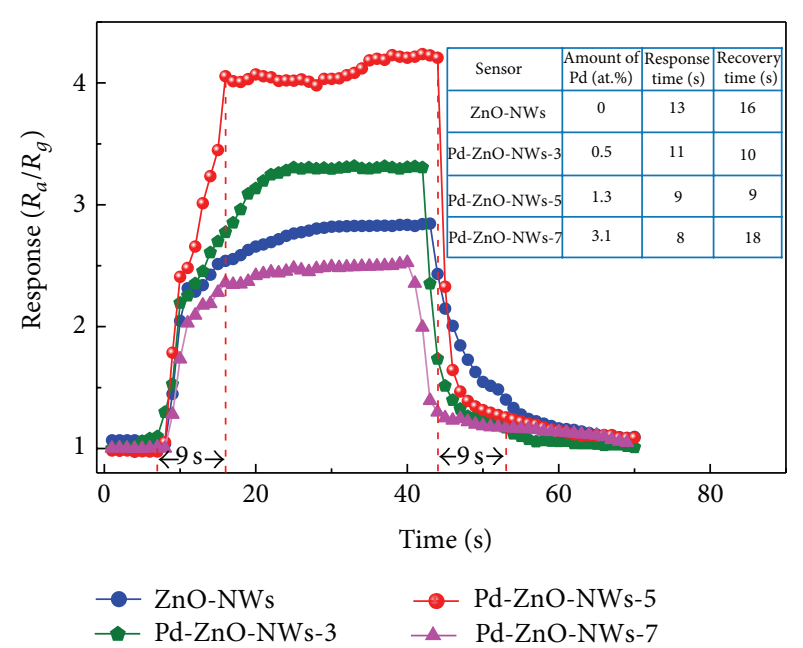

FIgURE 4: Transient responses of $\mathrm{ZnO}-\mathrm{NWs}$ and Pd-ZnO-NWs- $x$ $(x=3,5$, and 7) exposed to $200 \mathrm{ppm}$ ethanol.

$0.5 \%, 1.3 \%$, and $3.1 \%$ atomic percentage of $\mathrm{Pd}$ on the surface of $\mathrm{ZnO}-\mathrm{NWs}$. Figure 4 shows the response value and responserecovery time of the ZnO-NWs and Pd-ZnO-NWs- $x(x=3$, 5 and 7) sensors exposed to $200 \mathrm{ppm}$ ethanol at their own optimum operating temperature of $425^{\circ} \mathrm{C}$ and $325^{\circ} \mathrm{C}$. When the $\mathrm{Pd}$ concentration on the surface of samples is increased from 0.5 to 3.1 at. $\%, \mathrm{Pd}-\mathrm{ZnO}-\mathrm{NWs}-5$ shows an improved sensor performance in terms of response value (4.23) and response-recovery times ( $9 \mathrm{~s}$ and $9 \mathrm{~s}$ ), which are better than those of $\mathrm{ZnO}-\mathrm{NW}$ s and Pd-ZnO-NWs-3 as well as those of previously reported data (Table 2 ). A further increase of the $\mathrm{Pd}$ concentration leads to the increase of the recovery time and the deterioration of the sensitivity. 
TABLE 2: The Comparison with the fabrication parameters of Pd-ZnO-NWs sensors reported in the literature and our work.

\begin{tabular}{|c|c|c|c|c|c|}
\hline Structure & $\begin{array}{l}\text { Diameter/length } \\
\quad(\mathrm{nm} / \mu \mathrm{m})\end{array}$ & $\begin{array}{l}\text { Concentration } \\
(\mathrm{ppm})\end{array}$ & $\begin{array}{c}\text { Operating } \\
\text { temperature }\left({ }^{\circ} \mathrm{C}\right)\end{array}$ & Response $^{\mathrm{a}}(\%)$ & $\begin{array}{c}\text { Response/recovery } \\
\text { time (s) }\end{array}$ \\
\hline Pd-ZnO-NWs-5 (our work) & $70-100 / 5$ & 200 & 325 & 76.4 & $9 / 9$ \\
\hline Pd-decorated $\mathrm{ZnO}$ nanorods [22] & $70 / 0.5$ & 1530 & 200 & 94 & $14 / 70$ \\
\hline Pd-sensitized ZnO-NWs [20] & $50 / 3.5$ & 500 & 230 & 61.5 & $\begin{array}{c}\text { a few } \\
\text { seconds/more than } \\
100 \text { seconds }\end{array}$ \\
\hline $\begin{array}{l}\text { Pd-functionalized individual } \\
\mathrm{ZnO} \text { microwire [23] }\end{array}$ & $1000 / 50-200$ & 200 & 400 & 13 & $-1-$ \\
\hline $\begin{array}{l}\mathrm{Pd} / \mathrm{ZnO} \text { spheroidal and rod-like } \\
\text { nanoparticles [24] }\end{array}$ & $\begin{array}{c}10-20 \\
\text { width: } 10-20 \\
\text { length: } 20-50\end{array}$ & 250 & 400 & 65.7 & $15 /$ within minutes \\
\hline $\begin{array}{l}\mathrm{Pd} \text { incorporated } \mathrm{ZnO} \\
\text { nanoparticles }[20]\end{array}$ & 17 & 200 & 170 & 68 & $60 / 10$ \\
\hline
\end{tabular}

${ }^{\mathrm{a}}$ Applies $\left(R_{a}-R_{g}\right) / R_{a}$ for the response.

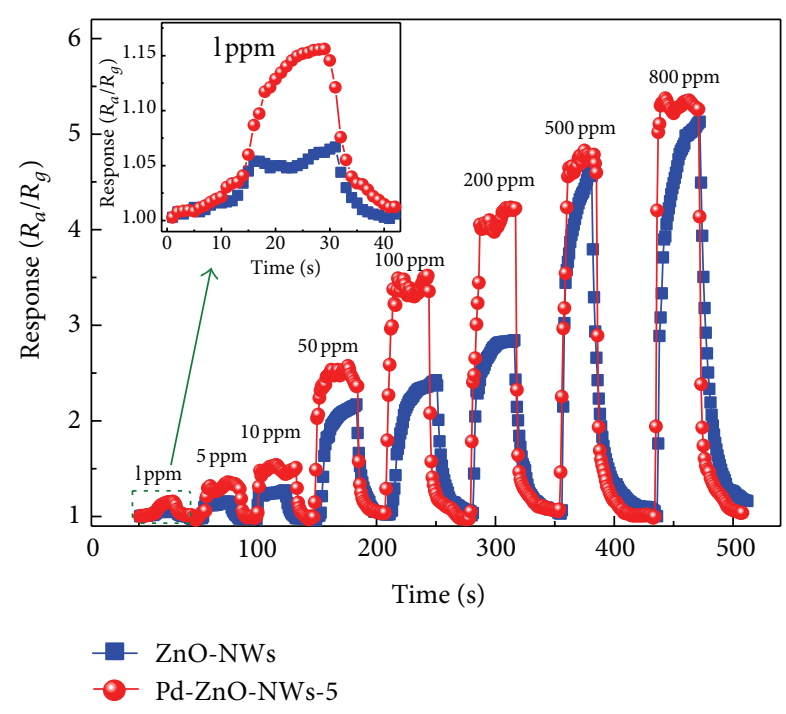

Figure 5: Dynamic responses of $\mathrm{ZnO}-\mathrm{NWs}$ and $\mathrm{Pd}-\mathrm{ZnO}-\mathrm{NWs}-$ 5 sensors to ethanol in the detection range from 1 to $800 \mathrm{ppm}$. The inserted image shows the partial magnified response curve of sensors exposed to $1 \mathrm{ppm}$ ethanol.

Figure 5 shows the dynamic responses of $\mathrm{ZnO}-\mathrm{NWs}$ and $\mathrm{Pd}-\mathrm{ZnO}-\mathrm{NW}-5$ exposed to different concentrations of ethanol at their optimum temperature, showing clearly a fast and repeatable response-recovery performance for ethanol. When the concentration of ethanol changes from 1 to $200 \mathrm{ppm}$, the response of $\mathrm{Pd}-\mathrm{ZnO}-\mathrm{NWs}-5$ is higher than that of $\mathrm{ZnO}-\mathrm{NW}$. When the concentration is larger than $500 \mathrm{ppm}$, however, the $\mathrm{ZnO}-\mathrm{NW}$ s and Pd-ZnO-NWs5 sensors show almost the same response. Remarkably, both sensors can detect ethanol of a concentration as low as $1 \mathrm{ppm}$, but $\mathrm{Pd}-\mathrm{ZnO}-\mathrm{NWs}-5$ sensor shows a better performance (insert of Figure 5) than the $\mathrm{ZnO}-\mathrm{NWs}$, with a response and recovery time of $12 \mathrm{~s}$ and $10 \mathrm{~s}$, respectively.

Figure 6(a) shows the response curves of two sensors at their optimum temperature as a function of ethanol concentration in the range of 1 to $800 \mathrm{ppm}$. Clearly, the response of $\mathrm{Pd}-\mathrm{ZnO}-\mathrm{NWs}-5$ sensor increases faster than that of $\mathrm{ZnO}$ NWs sensor. The Pd-ZnO-NWs-5 sensor also has a better linearity than that of $\mathrm{ZnO}-\mathrm{NWs}$ up to $100 \mathrm{ppm}$, indicating that $\mathrm{Pd}-\mathrm{ZnO}-\mathrm{NW}-5$ sensor is more favorable to detect low concentration ethanol. When the concentration of ethanol is increased to $500 \mathrm{ppm}$, the responses of two sensors increase slowly, due presumably to the saturation of both sensors.

3.3. Mechanistic Understanding of Ethanol Sensing. It is well known that chemisorbed oxygen plays a key role in electrical transmission of semiconducting metal oxides [30, 31], and the sensitivity of the gas sensor depends on the interaction between chemisorbed oxygen and sensing materials. As reactive oxygen, chemisorbed oxygen can be divided into $\mathrm{O}_{2}{ }^{-}, \mathrm{O}^{2-}$, and $\mathrm{O}^{-}$. Empirically, the response of the sensor can be expressed as follows [31]:

$$
\log (S-1)=\alpha \log C_{\text {gas }}+\log \beta,
$$

where $S$ is the response of sensor, $C_{\text {gas }}$ is the concentration of target gas, $\alpha$ and $\beta$ are constants, $\alpha$ is a value represents the species of oxygen ion on the surface of $\mathrm{ZnO}-\mathrm{NWs}$ [32]. It was reported that for $\alpha$ of 0.5 the chemisorbed oxygen ion on the surface is $\mathrm{O}^{2-}$ and for $\alpha$ of 1 , the chemisorbed oxygen ion is $\mathrm{O}^{-}$[31]. Figure 6(b) shows the linear relationship between the sensor response and the ethanol concentration. The slopes of the two lines $(0.61$ and 0.52 , resp.) are close to 0.5 , which means that the dominated species of the oxygen ion on $\mathrm{ZnO}$ surface are $\mathrm{O}^{2-}$ ions. These oxygen ions can trap electrons from $\mathrm{ZnO}$ and form a space-charge region which makes the resistance of sensor increase. When the reducing gas (such as ethanol) is injected into the chamber, the ionic oxygen reacts with ethanol and produces $\mathrm{CO}_{2}$ and $\mathrm{H}_{2} \mathrm{O}$ and then releases a large number of electrons. These released electrons will go back to the conduction band, leading to the decrease of metal oxide resistance. The reaction process can be described as follows [33]:

$$
\begin{gathered}
\mathrm{O}_{2}+\mathrm{e}^{-} \longrightarrow \mathrm{O}_{2}{ }^{-} \\
\mathrm{O}_{2}{ }^{-}+\mathrm{e}^{-} \longrightarrow 2 \mathrm{O}^{-}
\end{gathered}
$$




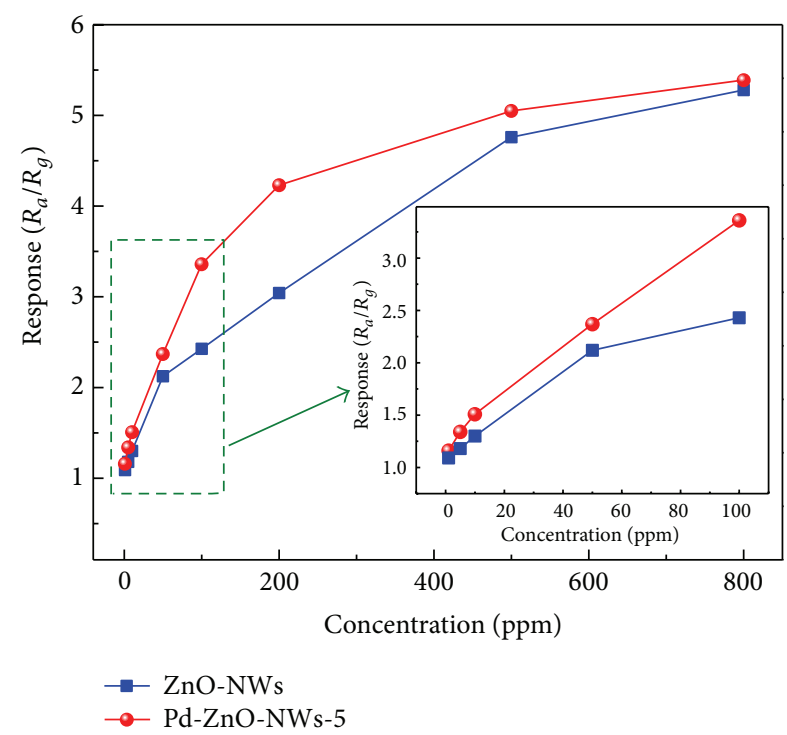

(a)

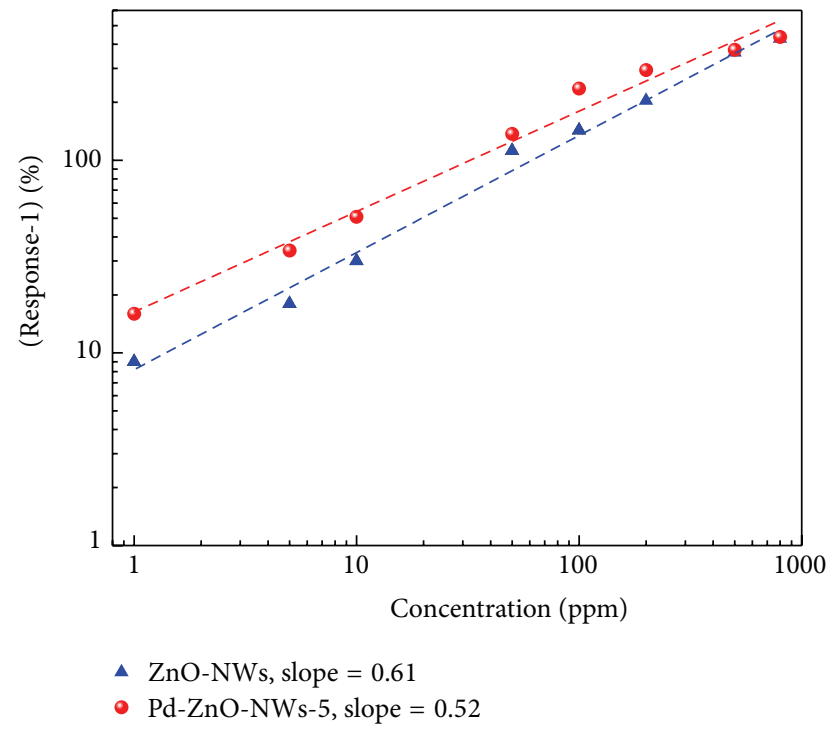

(b)

Figure 6: (a) Response of ZnO-NWs and Pd-ZnO-NWs-5 versus ethanol concentrations (the inserted image shows the partial magnified response curve of the two sensors exposed to $1-100 \mathrm{ppm}$ ethanol), (b) linear relationship between $\log (\operatorname{Response}-1)$ and $\log C_{\text {gas }}$.

$$
\begin{gathered}
\mathrm{O}^{-}+\mathrm{e}^{-} \longrightarrow \mathrm{O}^{2-} \\
\mathrm{C}_{2} \mathrm{H}_{5} \mathrm{OH}+6 \mathrm{O}^{2-} \longrightarrow 2 \mathrm{CO}_{2}+3 \mathrm{H}_{2} \mathrm{O}+12 \mathrm{e}^{-}
\end{gathered}
$$

Our data have shown that the additive Pd can improve the gas sensing properties of the $\mathrm{ZnO}$ sensors to ethanol. At high temperature, oxygen molecules can weakly bond to the catalytic atoms Pd [34], and the oxygen atom is produced in a complex dissociation reaction (4) [35]. This oxygen atom finally becomes negatively charged oxygen ion by trapping an electron from the surface of $\mathrm{ZnO}$ (5).

Consider the following:

$$
\begin{gathered}
2 \mathrm{Pd}+\mathrm{O}_{2} \longrightarrow 2 \mathrm{Pd}: \mathrm{O} \\
\mathrm{O}+\mathrm{e}^{-} \longrightarrow \mathrm{O}^{-}
\end{gathered}
$$

Meanwhile, because of the PdO attached on the surface of $\mathrm{ZnO}$, a heterojunction at the interface between $\mathrm{ZnO}$ ( $\mathrm{n}$ type semiconductor) and PdO (p-type semiconductor) will be formed as shown in Figure 7(a). The heterojunction leads to the band bending in the depletion layers [36]. The electrons transfer from n-type $\mathrm{ZnO}$ to $\mathrm{p}$-type $\mathrm{PdO}$, whereas the holes transfer from $\mathrm{PdO}$ to $\mathrm{ZnO}$ until the system reaches the equilibrium state. These charge transfers will lead to a wider depletion layer and a greater resistance. As the reaction processing, the electrons will pass through the depletion layers of heterojunction under the certain high temperature, which makes the depletion layer at the $\mathrm{PdO} / \mathrm{ZnO}$ interface once again become thin, facilitating the larger amount of electron transport between the $\mathrm{PdO}$ and $\mathrm{ZnO}$, and as a result, the response-recovery times and optimum operating temperature of the sensor decrease significantly compared to its undecorated counterpart $[22,24]$.
Simultaneously, ethanol molecule can also combine with the hole in $\mathrm{PdO}(6)$ and produce the intermediates, which will react with the $\mathrm{O}^{2-}$ on the n-type $\mathrm{ZnO}(7)$ and release more electrons. Such catalytic dissociation of ethanol on Pd nanoparticles lowers the activation energy, enhances the reaction velocity, and improves the performance of the sensor as a whole. The schematic model of the $\mathrm{ZnO}-\mathrm{NWs}$ and Pd$\mathrm{ZnO}-\mathrm{NWs}$ sensors when exposed to ethanol gas is shown in Figure 7(b).

Consider the following:

$$
\begin{gathered}
\mathrm{C}_{2} \mathrm{H}_{5} \mathrm{OH}+\mathrm{h}^{+} \longrightarrow \mathrm{CH}_{3} \mathrm{CH}_{2} \mathrm{O}+\mathrm{H}^{+} \\
\mathrm{CH}_{3} \mathrm{CH}_{2} \mathrm{O}+\mathrm{H}^{+}+6 \mathrm{O}^{2-} \longrightarrow 2 \mathrm{CO}_{2}+3 \mathrm{H}_{2} \mathrm{O}+11 \mathrm{e}^{-}
\end{gathered}
$$

\section{Conclusion}

ZnO-NWs were prepared by hydrothermal growth, showing high quality crystallinity and $c$-axis orientation. They were then used for gas sensing with or without Pd-decoration. Our results showed that the $\mathrm{ZnO}-\mathrm{NWs}$ and $\mathrm{Pd}-\mathrm{ZnO}-\mathrm{NWs}$ were more selective to ethanol in the presence of $\mathrm{CH}_{4}$, $\mathrm{CO}, \mathrm{CH}_{3} \mathrm{OH}$, and $\mathrm{CH}_{3} \mathrm{COCH}_{3}$. Comparing to the as-grown ZnO-NWs, Pd-ZnO-NWs showed a higher sensitivity, faster response, higher selectivity, and lower operating temperature. Typically, the response of Pd-ZnO-NWs was $57 \%$ higher and the optimum operating temperature was $100^{\circ} \mathrm{C}$ lower than those of $\mathrm{ZnO}-\mathrm{NWs}$. When exposed to $200 \mathrm{ppm}$ ethanol, the response and recovery time (both $9 \mathrm{~s}$ ) of Pd-ZnO-NWs5 were shorter than those of pure $\mathrm{ZnO}-\mathrm{NWs}$ (13s and $16 \mathrm{~s}$, resp.). These improvements could be attributed to the formation of the heterojunction between $\mathrm{PdO}$ and $\mathrm{ZnO}$. We believe that the Pd-ZnO-NWs hold a great potential for highperformance detection of ethanol gas. 


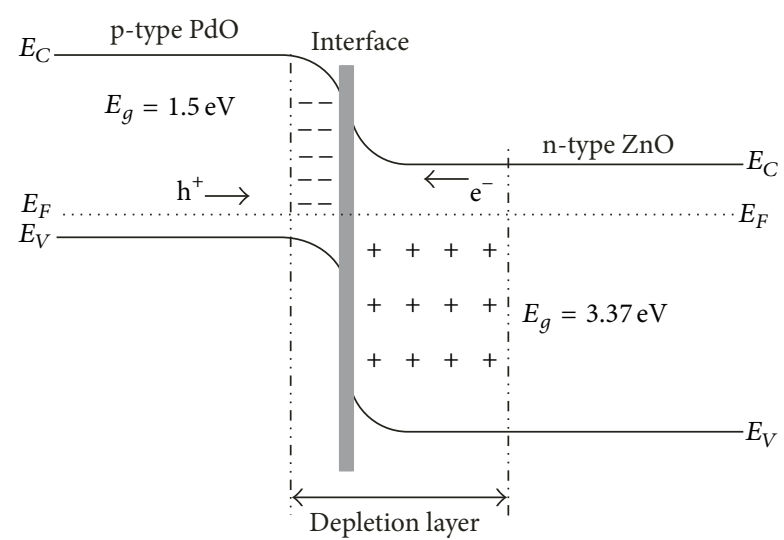

$E_{F}$ : fermi level

$E_{V}$ : valence band

$E_{C}:$ conduction band

(a)

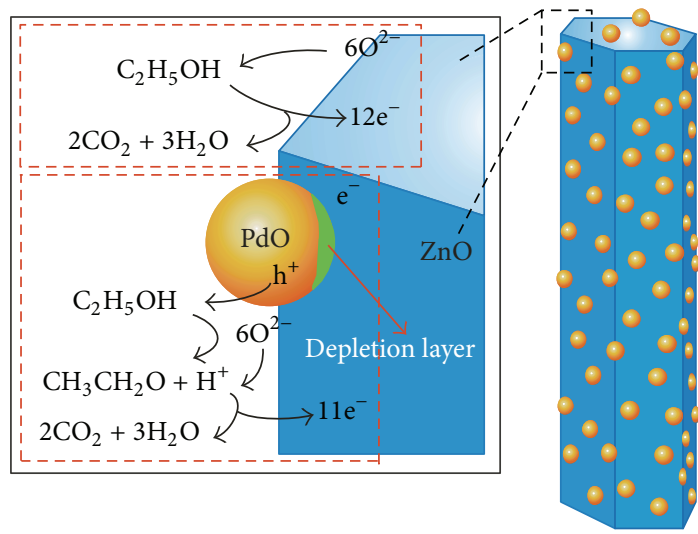

(b)

FIGURE 7: (a) Diagram of energy band structure for p-type PdO/ntype $\mathrm{ZnO}$ heterojunction, (b) schematic model of the $\mathrm{ZnO}-\mathrm{NW}$ s and $\mathrm{Pd}-\mathrm{ZnO}-\mathrm{NWs}$ sensors exposed to ethanol gas.

\section{Acknowledgments}

The authors thank the National Natural Science Foundation of China (Grant nos. 51205273 and 51205274), the Shanxi Province Science Foundation for Youths (Grant no. 2013021017-2), the Scientific and Technological Innovation Programs of Higher Education Institutions in Shanxi (Grant no. 20120007), the Shanxi Scholarship Council of China (Grant no. 2013-035), the Excellent Innovation Programs for Postgraduate in Shanxi Province (Grant no. 20133028), the Special/Youth Foundation of Taiyuan University of Technology (Grant nos. 2012L034 and 2012L011), and also the Excellent Graduate's Science and Technology Innovation Foundation of Taiyuan University of Technology (Grant no. 2013A005).

\section{References}

[1] G. Eranna, B. C. Joshi, D. P. Runthala, and R. P. Gupta, "Oxide materials for development of integrated gas sensors-a comprehensive review," Critical Reviews in Solid State and Materials Sciences, vol. 29, no. 3-4, pp. 111-188, 2004.

[2] H.-W. Ryu, B.-S. Park, S. A. Akbar et al., "ZnO sol-gel derived porous film for CO gas sensing," Sensors and Actuators B, vol. 96, no. 3, pp. 717-722, 2003.

[3] J. X. Wang, X. W. Sun, A. Wei et al., "Zinc oxide nanocomb biosensor for glucose detection," Applied Physics Letters, vol. 88, no. 23, Article ID 233106, 2006.

[4] N. Al-Hardan, M. J. Abdullah, and A. A. Aziz, "The gas response enhancement from $\mathrm{ZnO}$ film for $\mathrm{H}_{2}$ gas detection," Applied Surface Science, vol. 255, no. 17, pp. 7794-7797, 2009.

[5] E. Hosono, S. Fujihara, I. Honma, and H. Zhou, "The fabrication of an upright-standing zinc oxide nanosheet for use in dyesensitized solar cells," Advanced Materials, vol. 17, no. 17, pp. 2091-2094, 2005.

[6] W. I. Park, J. S. Kim, G.-C. Yi, M. H. Bae, and H.-J. Lee, "Fabrication and electrical characteristics of high-performance $\mathrm{ZnO}$ nanorod field-effect transistors," Applied Physics Letters, vol. 85, no. 21, pp. 5052-5054, 2004.

[7] S. Liang, H. Sheng, Y. Liu, Z. Huo, Y. Lu, and H. Shen, "ZnO Schottky ultraviolet photodetectors," Journal of Crystal Growth, vol. 225, no. 2-4, pp. 110-113, 2001.

[8] Z. T. Han, S. S. Li, J. K. Chu, and Y. Chen, "Electrospun $\mathrm{Pd}$-doped $\mathrm{ZnO}$ nanofibers for enhanced photocatalytic degradation of methylene blue," Journal of Sol-Gel Science and Technology, vol. 66, no. 1, pp. 139-144, 2013.

[9] D. Mishra, A. Srivastava, A. Srivastava, and R. K. Shukla, "Bead structured nanocrystalline $\mathrm{ZnO}$ thin films: synthesis and LPG sensing properties," Applied Surface Science, vol. 255, no. 5, pp. 2947-2950, 2008.

[10] K. J. Chen, F. Y. Hung, S. J. Chang, and S. J. Young, "Optoelectronic characteristics of UV photodetector based on $\mathrm{ZnO}$ nanowire thin films," Journal of Alloys and Compounds, vol. 479, no. 1-2, pp. 674-677, 2009.

[11] P. Bhattacharyya, P. K. Basu, H. Saha, and S. Basu, "Fast response methane sensor using nanocrystalline zinc oxide thin films derived by sol-gel method," Sensors and Actuators B, vol. 124, no. 1, pp. 62-67, 2007.

[12] C. S. Prajapati and P. P. Sahay, "Alcohol-sensing characteristics of spray deposited $\mathrm{ZnO}$ nano-particle thin films," Sensors and Actuators B, vol. 160, no. 1, pp. 1043-1049, 2011.

[13] T.-J. Hsueh, Y.-W. Chen, S.-J. Chang et al., "ZnO nanowirebased $\mathrm{CO}$ sensors prepared on patterned $\mathrm{ZnO}: \mathrm{Ga} / \mathrm{SiO} 2 / \mathrm{Si}$ templates," Sensors and Actuators B, vol. 125, no. 2, pp. 498-503, 2007.

[14] H. Zhang, D. Yang, D. Li, X. Ma, S. Li, and D. Que, "Controllable growth of $\mathrm{ZnO}$ microcrystals by a capping-molecule-assisted hydrothermal process," Crystal Growth and Design, vol. 5, no. 2, pp. 547-550, 2005.

[15] X. Jiaqiang, C. Yuping, C. Daoyong, and S. Jianian, "Hydrothermal synthesis and gas sensing characters of $\mathrm{ZnO}$ nanorods," Sensors and Actuators B, vol. 113, no. 1, pp. 526-531, 2006.

[16] N. Hongsith, C. Viriyaworasakul, P. Mangkorntong, N. Mangkorntong, and S. Choopun, "Ethanol sensor based on $\mathrm{ZnO}$ and $\mathrm{Au}$-doped $\mathrm{ZnO}$ nanowires," Ceramics International, vol. 34, no. 4, pp. 823-826, 2008.

[17] F.-C. Huang, Y.-Y. Chen, and T.-T. Wu, "A room temperature surface acoustic wave hydrogen sensor with $\mathrm{Pt}$ coated $\mathrm{ZnO}$ nanorods," Nanotechnology, vol. 20, no. 6, Article ID 065501, 2009. 
[18] P. Mitra and H. S. Maiti, "A wet-chemical process to form palladium oxide sensitiser layer on thin film zinc oxide based LPG sensor," Sensors and Actuators B, vol. 97, no. 1, pp. 49-58, 2004.

[19] Q. Xiang, G. Meng, Y. Zhang et al., "Ag nanoparticle embedded$\mathrm{ZnO}$ nanorods synthesized via a photochemical method and its gas-sensing properties," Sensors and Actuators B, vol. 143, no. 2, pp. 635-640, 2010.

[20] B. Baruwati, D. K. Kumar, and S. V. Manorama, "Hydrothermal synthesis of highly crystalline $\mathrm{ZnO}$ nanoparticles: a competitive sensor for LPG and EtOH," Sensors and Actuators B, vol. 119, no. 2, pp. 676-682, 2006.

[21] T.-J. Hsueh, S.-J. Chang, C.-L. Hsu, Y.-R. Lin, and I.-C. Chen, "Highly sensitive $\mathrm{ZnO}$ nanowire ethanol sensor with Pd adsorption," Applied Physics Letters, vol. 91, no. 5, Article ID 053111, 2007.

[22] S. Roy, N. Banerjee, C. Sarkar, and P. Bhattacharyya, "Development of an ethanol sensor based on CBD grown ZnO nanorods," Solid-State Electronics, vol. 87, pp. 43-50, 2013.

[23] G. Y. Chai, O. Lupan, E. V. Rusu et al., "Functionalized individual $\mathrm{ZnO}$ microwire for natural gas detection," Sensors and Actuators A, vol. 176, pp. 64-71, 2012.

[24] C. Liewhiran, A. R. Camenzind, A. Teleki, S. E. Pratsinis, and S. Phanichphant, "Doctor-bladed thick films of flame-made $\mathrm{Pd} / \mathrm{ZnO}$ nanoparticles for ethanol sensing," Current Applied Physics, vol. 8, no. 3-4, pp. 336-339, 2008.

[25] J.-H. Tian, J. Hu, S.-S. Li et al., "Improved seedless hydrothermal synthesis of dense and ultralong $\mathrm{ZnO}$ nanowires," Nanotechnology, vol. 22, no. 24, Article ID 245601, 2011.

[26] X. Li, Y. Chang, and Y. Long, "Influence of Sn doping on $\mathrm{ZnO}$ sensing properties for ethanol and acetone," Materials Science and Engineering C, vol. 32, no. 4, pp. 817-821, 2012.

[27] Y.-H. Hsu, J. Lin, and W. C. Tang, "RF sputtered piezoelectric zinc oxide thin film for transducer applications," Journal of Materials Science: Materials in Electronics, vol. 19, no. 7, pp. 653-661, 2008.

[28] M. Zhao, X. Wang, J. Cheng, L. Zhang, J. Jia, and X. Li, "Synthesis and ethanol sensing properties of Al-doped $\mathrm{ZnO}$ nanofibers," Current Applied Physics, vol. 13, no. 2, pp. 403-407, 2012.

[29] Y. Zeng, Z. Lou, L. Wang et al., "Enhanced ammonia sensing performances of Pd-sensitized flowerlike $\mathrm{ZnO}$ nanostructure," Sensors and Actuators B, vol. 156, no. 1, pp. 395-400, 2011.

[30] W. Zeng, T. Liu, and Z. Wang, "Impact of Nb doping on gassensing performance of $\mathrm{TiO}_{2}$ thick-film sensors," Sensors and Actuators B, vol. 166-167, pp. 141-149, 2012.

[31] S. Choopun, A. Tubtimtae, T. Santhaveesuk, S. Nilphai, E. Wongrat, and N. Hongsith, "Zinc oxide nanostructures for applications as ethanol sensors and dye-sensitized solar cells," Applied Surface Science, vol. 256, no. 4, pp. 998-1002, 2009.

[32] Y. H. Shi, M. Q. Wang, C. Hong et al., "Multi-junction joints network self-assembled with converging $\mathrm{ZnO}$ nanowires as multi-barrier gas sensor," Sensors and Actuators B, vol. 177, pp. 1027-1034, 2012.

[33] P. P. Sahay, "Zinc oxide thin film gas sensor for detection of acetone," Journal of Materials Science, vol. 40, no. 16, pp. 4383-4385, 2005.

[34] K. V. Gurav, P. R. Deshmukh, and C. D. Lokhande, "LPG sensing properties of Pd-sensitized vertically aligned $\mathrm{ZnO}$ nanorods," Sensors and Actuators B, vol. 151, no. 2, pp. 365-369, 2011.

[35] V. R. Shinde, T. P. Gujar, and C. D. Lokhande, "Enhanced response of porous $\mathrm{ZnO}$ nanobeads towards LPG: effect of Pd sensitization," Sensors and Actuators B, vol. 123, no. 2, pp. 701706, 2007.

[36] G. Eranna, B. C. Joshi, D. P. Runthala, and R. P. Gupta, "Oxide materials for development of integrated gas sensors-a comprehensive review," Critical Reviews in Solid State and Materials Sciences, vol. 29, no. 3-4, pp. 111-188, 2004. 

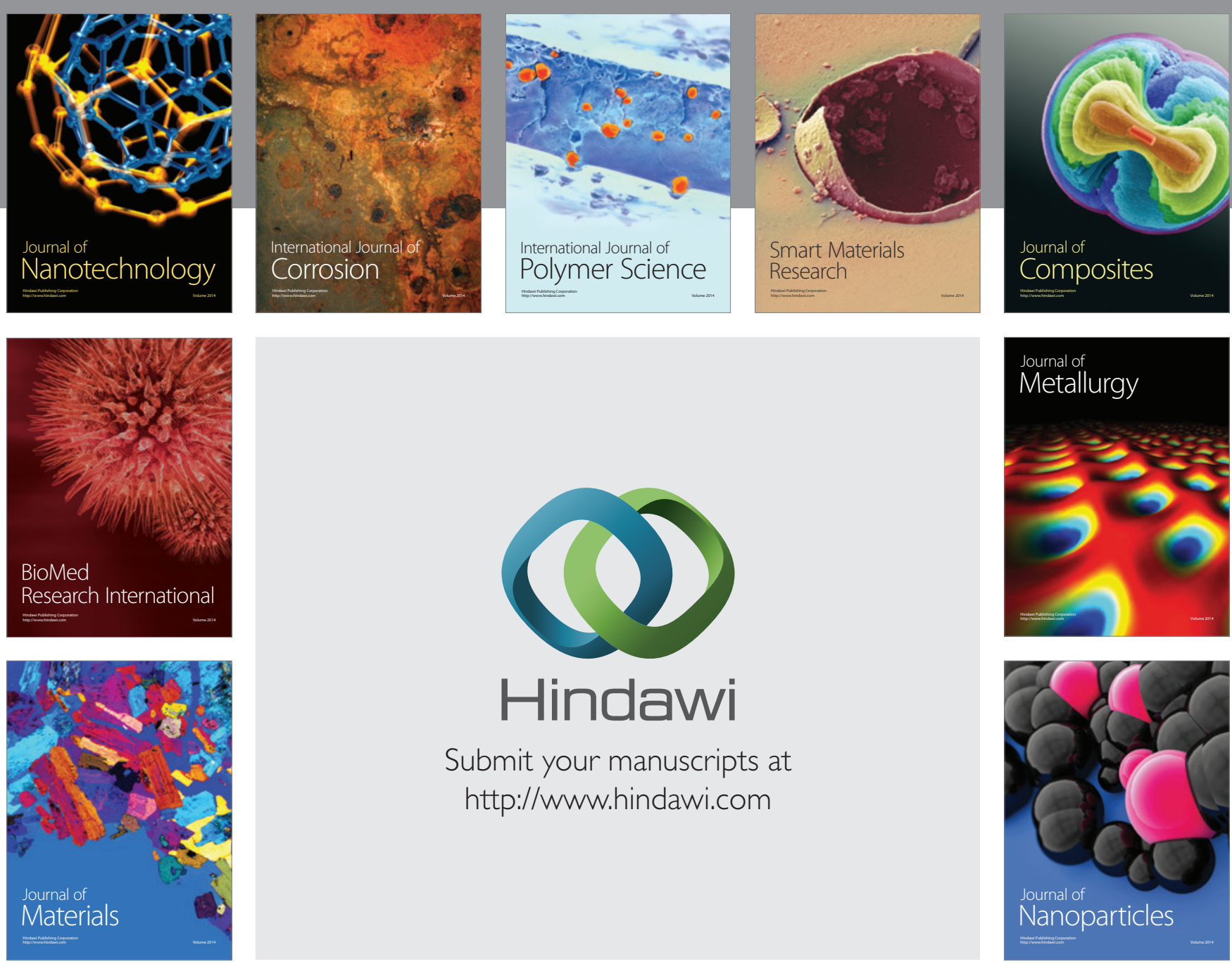

Submit your manuscripts at http://www.hindawi.com
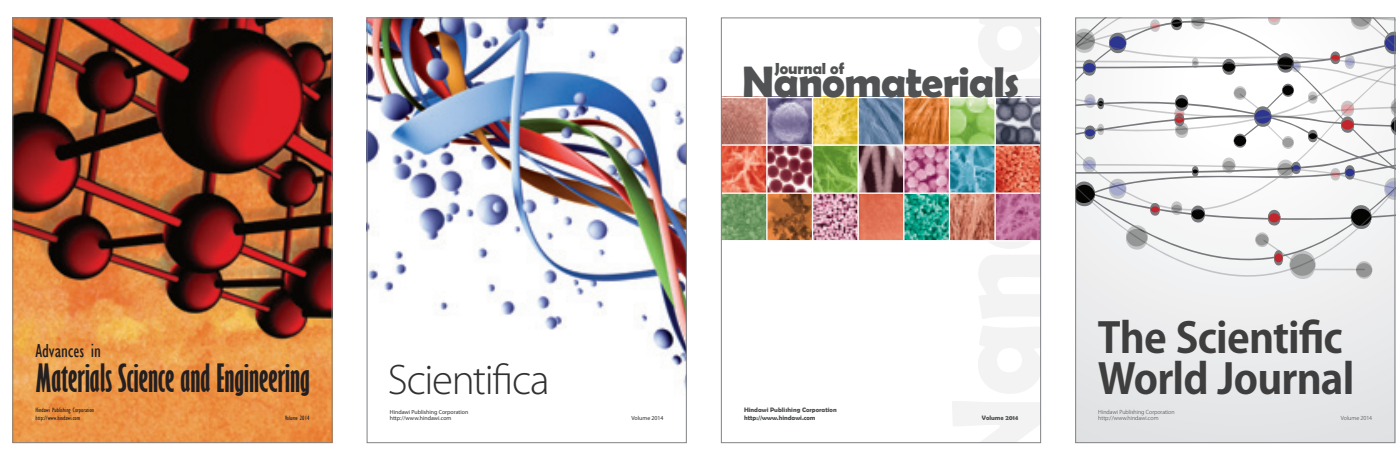

\section{The Scientific World Journal}
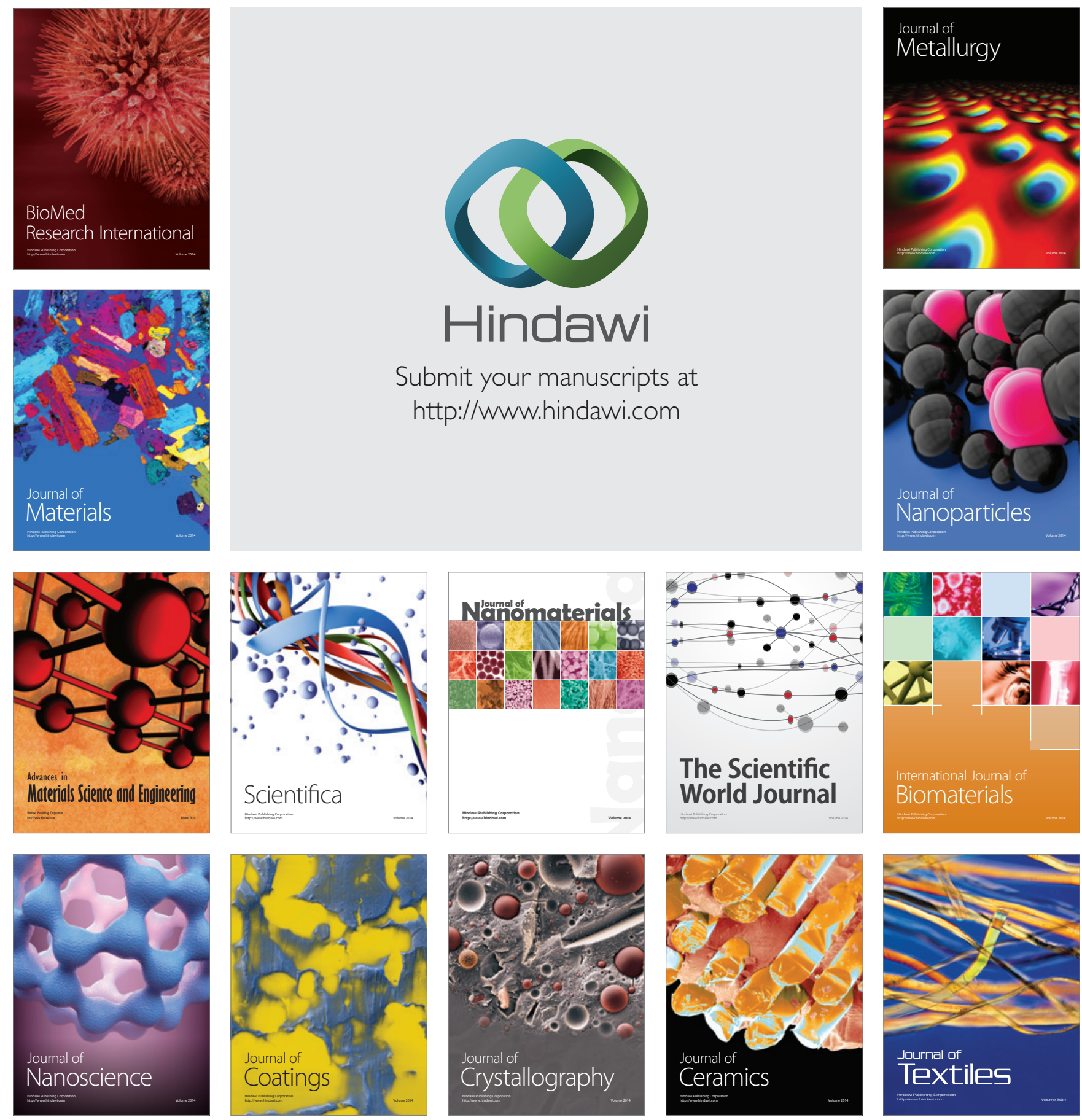